\title{
BOWEL PREPARATION BEFORE COLONOSCOPY FOR CHILDREN: comparison of efficacy of three different methods
}

\author{
Seyed Mohsen DEHGHANI ${ }^{1}$, Hazhir JAVAHERIZADEH ${ }^{2}$, Mahmood HAGHIGHAT ${ }^{1}$, \\ Mohammad-Hadi IMANIEH ${ }^{1}$ and Saeed GHANBARI ${ }^{3}$
}

Received 9/4/2015

Accepted 22/4/2015

\begin{abstract}
Background - Colonoscopy is an important diagnostic and therapeutic procedure. Adequate bowel preparation is mandatory. Several regimens were discussed in the literature. Among the drugs which has recently used, polyethylene glycol is one of the most popular agents. Objectives - The aim of this study was to compare efficacy of three different methods for 1 day preparation before colonoscopy. Methods - This study included children with the range of ages (2-21) who had an indication of colonoscopy. Exclusion criteria were based on the history of previous surgery, parental disagreement, and patients who did not use preparation protocol. Three methods for bowel preparation were studied: 1- Polyethylene glycol only; 2- Polyethylene glycol and bisacodyl suppositories; 3Polyethylene glycol plus normal saline enema. Boston Bowel Preparation Score was used for evaluation of preparation. SPSS version 16.0 (Chicago, IL, USA) were used for data analysis. Results - In this study 83 cases completed the bowel preparation completely. Acceptable bowel preparation was seen in 24 (85.71\%), $36(94.73 \%)$, and $14(82.35 \%)$ of cases in PEG, PEG + bisacodyl, and PEG + normal saline enema groups respectively. PEG + bisacodyl suppositories was more effective than PEG + normal saline for the preparation of the first segment $(P=0.05)$. For second and third segment of colon, BPPS score was higher in PEG + bisacodyl suppositories compared to other regimens, but this difference was not statistically significant. Conclusion - There was no significant difference between 1 day colonoscopy regimens in terms of bowel preparation score. Lowest score was seen in PEG + enema group compared to other group.
\end{abstract}

HEADINGS - Bisacodyl. Colonoscopy. Polyethylene glycols.

\section{INTRODUCTION}

Colonoscopy is an important diagnostic and therapeutic procedure. Adequate bowel preparation is mandatory. Several regimens were discussed in the literature. Among the drugs which has recently used, polyethylene glycol is one of the most popular agents ${ }^{(6)}$. One day regimen is currently favorable among gastroenterologist and patients. Recent study by Sorser et al. showed equal efficacy of one day and 3 day bowel preparation ${ }^{(8)}$. In our country, PEG and bisacodyl suppositories are widely available and are used for bowel preparation. Kinservik and Friedhoff in their study showed polyethylene glycol was a safe method without significant adverse effect for the bowel preparation or the treatment of constipation ${ }^{(4)}$. In this study three different 1 day methods were compared in terms of their efficacy for bowel cleansing.

\section{METHODS}

In this study every children aged 2-21 years who have indication for colonoscopy were included. Ages of 21 were included in our study according to Terry et al. study ${ }^{(9)}$. Sample size estimation was done according to previous literatures which were similar to the age of the case and methodology. Terry et al. included 30 cases in two groups and Sorser et al. included 32 cases for two groups ${ }^{(8,9)}$. In our study 87 cases were included. Patients were randomly placed in three groups regardless their age and sex. Exclusion criteria were based on the history of previous abdominal surgery, parental disagreement, patients who did not use prescribed drugs, history of prior colonoscopy, and history of laxative or stimulant medication before colonoscopy. Three methods for preparation were included: 1- Polyethylene glycol only; 2- Polyethylene

Declared conflict of interest of all authors: none

Disclosure of funding: no funding received

${ }_{1}^{1}$ Gastroenterohepatology Research Center, Nemazee Teaching Hospital, Shiraz University of Medical Sciences, Shiraz, Iran; ${ }^{2}$ Department of Pediatric Gastroenterology, Nemazee Teaching Hospital, Shiraz University of Medical Sciences, Shiraz, Iran; ${ }^{3}$ Department of Biostatistics, Medical School, Shiraz University of Medical Sciences, Shiraz, Iran. Correspondence: Hazhir Javaherizadeh. Department of Pediatric Gastroenterology, Nemazee Teaching Hospital, Shiraz University of Medical Sciences, Shiraz, Iran. E-mail: hazhirja@yahoo.com 
glycol and bisacodyl suppositories; 3- Polyethylene glycol and normal saline enema.

Polyethylene glycol powder was available in our country as 70 gram per package. For children weighed $\geq 45 \mathrm{~kg}$, four packages were solved in 2 liter of mineral water. For children weighted $<45 \mathrm{~kg}$, two packages were solved in 1 lit of mineral water. Our dosage was similar to Walia et al. ${ }^{(10)}$ study with minimal difference. Three bisacodyl suppositories were used for group 2 starting from 8 am of the day prior to colonoscopy for q8r. Normal saline enema (volume $500 \mathrm{cc}$ ) was done two times starting from the day prior to colonoscopy at $12 \mathrm{hr}$ interval. Liquid diet were prescribed the day before colonoscopy. Validated Bowel Preparation scale (BBPS) was used for evaluation of bowel preparation ${ }^{(3,5)}$. BPPS score was developed by Lai et al. in order to develop a valid a reliable scale for use in colonoscopy outcome research ${ }^{(5)}$. According to BBPS points are assigned as follows.

BPPS score is a 10 point scale with minimum score is 0 and maximum score is 9 . In this scoring system, colon divided into three parts: Right colon (including the cecum and ascending colon), the transverse colon (including the hepatic and splenic flexure) and the left colon (including the descending colon, sigmoid colon and rectum). Each part will be assigned a score $0-3$ according to following criteria:

" $0=$ Unprepared colon segment with mucosa not seen due to solid stool that cannot be cleared"

$1=$ Portion of mucosa of the colon segment seen, but other areas of the colon segment not well seen due to staining, residual stool and/or opaque liquid.

$2=$ Minor amount of residual staining, small fragments of stool and/or opaque liquid, butmucosa of colon segment seen well.

3 = Entire mucosa of colon segment seen well with no residual staining, small fragmentsof stool or opaque liquid."(5).

\section{Sum of scores of three parts will be 0 to 9}

Acceptable bowel preparation is defined when BBPS $\geq 5^{(1)}$. Excellent bowel preparation is defined when BPPS $\geq 7^{(1)}$. Poor bowel preparation was defined as BPPS $\leq 4^{(1)}$.

This study was approved by ethical committee of the university (Ethic code: CT-P-9365-6485).SPSS (Chicago, IL, USA) was used for data analysis. All colonoscopies were performed under general anesthesia. This study was registered in Iranian Registry of Clinical Trials (IRCT) with no.IRCT2014110919881N1.

\section{RESULTS}

Failure to follow preparation protocol was seen in 10 , 2 , and 5 cases in NS, PEG+bisacodyl, and PEG groups respectively. In this study, 83 cases that completed regimens exactly were analyzed. Mean \pm SE of age of the cases was $9.28 \pm 0.56$ (Min: 1.5, Max: 21). Demographic features of groups were shown in Table 1. No significant difference was found between three groups in terms of mean age $(P=0.650)$.
BBPS was zero in four cases. Of these cases two were from PEG group and two from PEG+N/S group. BPPS was nine in 8, 22, and 5 cases of PEG, PEG+ bisacodyl, and PEG+N/S groups respectively.

For first segment bowel preparation, BBPS (Mean \pm SE) was higher in PEG + bisacodyl group $(2.68 \pm 0.10)$ compared PEG (2.46 \pm 0.15$)$ and PEG + normal saline enema $(2.11 \pm 0.24)$ groups $(P=0.04)$ (Table 2 and Figure 1$)$.

Mean \pm SE of BPPS score was higher for PEG+ bisacodyl (2.55 \pm 0.11$)$ group compared to PEG $(2.28 \pm 0.17)$ and PEG + normal saline enema $(2.23 \pm 0.25)$ for second segment of colon, but was not statistically significant $(P=0.313)$ (Table 2 and Figure 2).

For the third segment of colon, mean $\pm \mathrm{SE}$ was higher in PEG + bisacodyl group $(2.31 \pm 0.14)$ compared to PEG (1.89 \pm 0.22$)$ and PEG + normal saline enema group $(1.94 \pm 0.24)$, but these difference was not statistically significant (Table 2 and Figure 3).

TABLE 1. Demographic features of groups

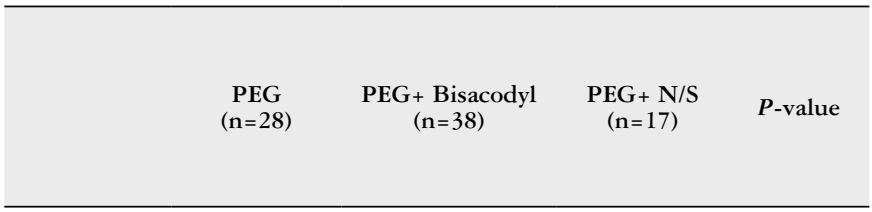

$\begin{array}{lrrrr}\begin{array}{l}\text { Mean age } \\ (\text { Mean } \pm \text { SE) }\end{array} & 9.51 \pm 0.92 & 9.43 \pm 0.87 & 8.47 \pm 1.22 & 0.798\end{array}$

Sex $\quad \mathrm{M}=16, \mathrm{~F}=12 \quad \mathrm{M}=27, \mathrm{~F}=13 \quad \mathrm{M}=8, \mathrm{~F}=9 \quad 0.468$

TABLE 2. Boston Bowel Preparation Score among three groups of cases

$\begin{array}{cccc}\text { PEG } & \text { PEG }+ \text { Bisacodyl } & \text { PEG }+ \text { Normal } & \\ (\mathrm{n}=28) & (\mathrm{n}=38) & \begin{array}{c}\text { Saline } \\ (\mathrm{n}=17)\end{array} & P \text {-value }\end{array}$

$\begin{array}{lllll}\text { First segment } & 2.46 \pm 0.15 & 2.68 \pm 0.10 & 2.11 \pm 0.24 & 0.063\end{array}$

Second segment

(Mean + SE)

$2.55 \pm 0.11$

$2.23 \pm 0.25$

0.415

Third segment

(Mean \pm SE)

$2.31 \pm 0.14$

$1.94 \pm 0.24$

0.382

$\begin{array}{lllll}\begin{array}{l}\text { Total } \\ (\text { Mean } \pm \text { SE) }\end{array} & 6.64 \pm 0.46 & 7.44 \pm 0.35 & 6.23 \pm 0.67 & 0.240\end{array}$ 


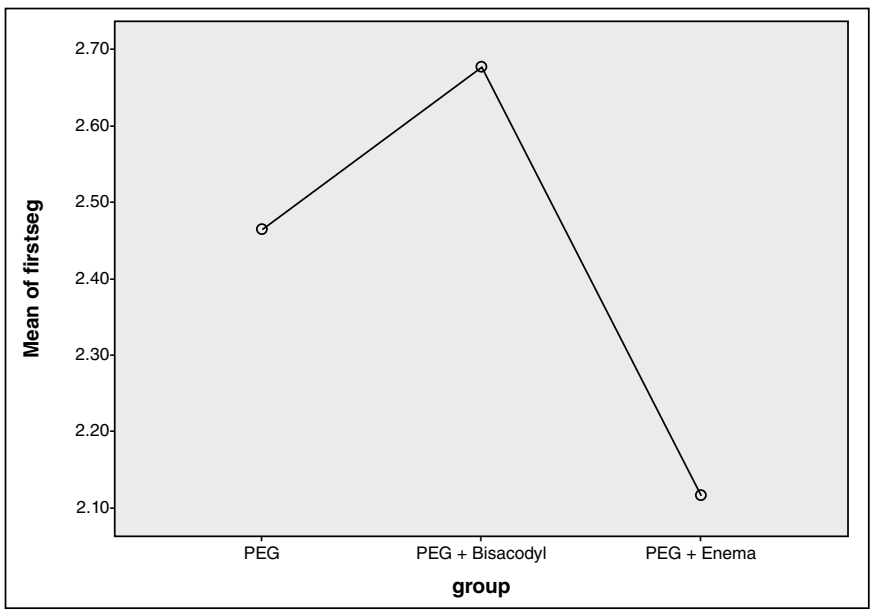

FIGURE 1. Mean of BPPS among three groups of cases for the preparation of the first segment

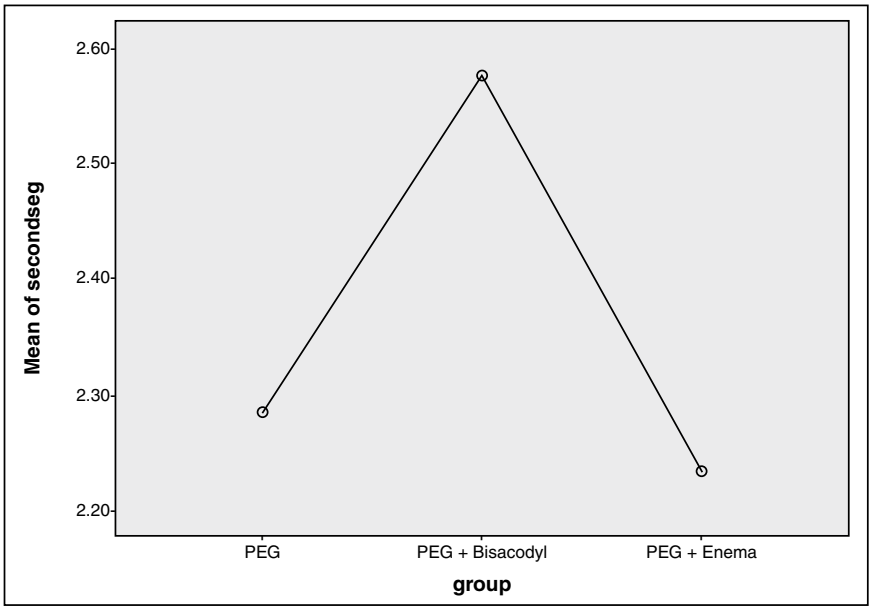

FIGURE 2. Mean of BPPS among three groups of cases for the bowel preparation of the second segment of colon

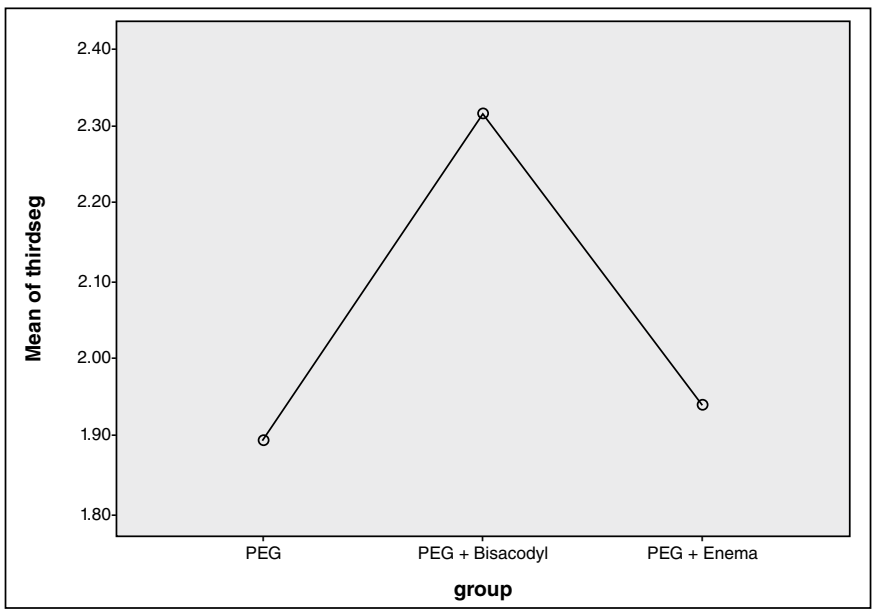

FIGURE 3. Mean of BPPS among three groups of cases for the bowel preparation of the third segment

\section{DISCUSSION AND CONCLUSION}

There was no significant difference between PEG, PEG + bisacodyl, and PEG with normal saline enema in terms of score of bowel preparation. In the study by Terry et al., they showed clear superiority of PEG versus senna ${ }^{(9)}$. In another study from South Korea, there was no difference between PEG only regimen versus PEG + bisacodyl in terms of quality of bowel preparation before colonoscopy ${ }^{(2)}$.

In our study, PEG + bisacodyl regimen had the highest score compared to PEG only preparation, but this difference was not statistically significant. In the study by Phatak et al., they recommended PEG + oral bisacodyl as a safe and effective methods ${ }^{(7)}$. Our study had lower sample size and bisacodyl suppositories were used instead of oral bisacodyl.

The mean total of BPPS in Abbas et al. ${ }^{(1)}$ study was 6.16 which was slightly lower than our study (mean $=6.64$ ). This difference may be due to that we included cases who consumed all of preparation liquid. Some cases in Abbas et al. study didn't use all of the liquid ${ }^{(1)}$.

Of 28 cases who had bowel preparation with PEG, 8 $(28.57 \%)$ cases had maximum score. In the study by Abbas et al., one case had maximum score ${ }^{(1)}$. The least score was 3 in the study by Abbas et al. ${ }^{(1)}$. But in our study the minimum score was zero in two cases.

Acceptable bowel preparation was defined BPPS $\geq 5$ in Abbas et al. study ${ }^{(1)}$. In their study, $77 \%$ of cases had BPPS $\geq 5^{(1)}$. In our study $24(85.71 \%)$ of cases, had acceptable bowel preparation among subjects receiving only PEG. Acceptable bowel preparation in PEG + bisacodyl and PEG + normal saline enema groups was seen in $36(94.73 \%)$ and $14(82.35 \%)$ of cases respectively which had slightly difference with PEG group. In the study by Sorser et al., of 18 cases who underwent one-day bowel preparation, $100 \%$ efficacy with PEG was noted ${ }^{(8)}$. Criteria for evaluation of bowel preparation were similar between Abbas et al.(1) study and our study.

Poor bowel preparation was noted in one case in Abbas et al. study ${ }^{(1)}$. In our study poor bowel preparation was seen in three cases in PEG group. In PEG + bisacodyl group, four cases showed poor bowel preparation. In PEG + N/S group, no subjects showed poor bowel preparation.

As mentioned above, PEG+ normal saline enema had no significant superiority against PEG only preparation. PEG + bisacodyl group had higher BPPS compared with other groups. Although it was not statistically significant, but in practice it may be more appropriate than PEG + normal saline enema.

In Abbas et al. study, 93.5\% of cases were able to complete the regimen ${ }^{(1)}$. In our study, of 100 cases, 83 cases were followed preparation protocol accurately. Most of these patients took other drugs (in addition to our recommendation) or changing their protocol by other health care personnel.

\section{Limitation}

The main limitation of this study was sample size and it was due to uncooperative child or parents. Another 
limitation is we didn't evaluate cases about constipation. Patient with constipation may respond poorly to bowel preparation.

\section{ACKNOWLEDGMENT}

This paper was issued from fellowship thesis of Dr. Hazhir Javaherizadeh and supported by research affairs of Shiraz University of Medical Sciences. The authors would like to thank personnel at Center for Development of Clinical Research of Nemazee Teaching Hospital.

\section{Authors' contributions}

Dehghani SM: main idea and data collection; Javaherizadeh $\mathrm{H}$ : writing proposal, data collection and manuscript writing; Haghighat M: supervision and manuscript revision; Imanieh MH: literature search and data collection; Ghanbari S: design of the study and data analysis.

Dehghani SM, Javaherizadeh H, Haghighat M, Imanieh MH, Ghanbari S. Preparo intestinal prévio à colonoscopia em crianças: comparação de três métodos diferentes. Arq Gastroenterol. 2015,52(4):xxx.

RESUMO - Contexto - A colonoscopia é um procedimento diagnóstico e terapêutico importante. A preparação intestinal adequada é obrigatória. Vários esquemas são discutidos na literatura. Dentre as drogas que se têm usado recentemente, o polietilenoglicol é um dos agentes mais utilizados. Objetivo - O objetivo deste estudo foi comparar a eficácia de três métodos diferentes para a preparação feita 1 dia antes de colonoscopia. Métodos Este estudo incluiu crianças com a gama de idades entre 2 e 21 anos, que tinham indicação de colonoscopia. Os critérios de exclusão foram baseados em história da cirurgia anterior, não aprovação dos pais e pacientes que não utilizaram o protocolo de preparação. Três métodos para a preparação do intestino foram estudados: 1-polietilenoglicol; 2 - polietilenoglicol e bisacodil supositórios; 3 - polietilenoglicol e enema de solução salina. O escore de Boston para preparação intestinal foi usado para a avaliação e os dados foram analisados pelo SPSS versão 16.0 (Chicago, Il, USA). Resultados - Um total de 83 pacientes concluiu completamente o preparo intestinal. Houve preparo aceitável em $24(85,71 \%), 36(94,73 \%)$ e 14 (82,35\%) dos casos, nos grupos PEG, PEG + bisacodil e PEG + enema salino, respectivamente. PEG + bisacodil supositórios foi mais eficaz do que a PEG + solução salina para a preparação do primeiro segmento $(P=0,05)$. Para segundo e terceiro segmento do cólon, a pontuação de BPPS foi maior no grupo PEG + bisacodil supositórios em comparação com outros regimes, mas essa diferença não foi estatisticamente significativa. Conclusão - Não houve nenhuma diferença significativa entre os regimes de preparo para colonoscopia de um dia em termos de pontuação de preparação do intestino. A nota mais baixa foi vista no grupo PEG + enema em comparação com outros grupos.

DESCRITORES - Bisacodil. Colonoscopia. Polietilenoglicóis.

\section{REFERENCES}

1. Abbas MI, Nylund CM, Bruch CJ, Nazareno LG, Rogers PL. Prospective evaluation of 1-day polyethylene glycol-3350 bowel preparation regimen in children. J Pediatr Gastroenterol Nutr. 2013;56(2):220-4.

2. Bang KB, Jeong EH, Jeong WS, Chae HB, Kim NH, Lee TH, et al. [Efficacy of bisacodyl given as part of a polyethylene glycol-based bowel preparation prior to colonoscopy in hospitalized patients: a prospective ramdomized trial]. Korean J Gastroenterol. 2014;64(5):268-77.

3. Kim EJ, Park YI, Kim YS, Park WW, Kwon SO, Park KS, et al. A Korean experience of the use of Boston bowel preparation scale: a valid and reliable instrument for colonoscopy-oriented research. Saudi J Gastroenterol. 2014;20(4):219-24.

4. Kinservik MA, Friedhoff MM. The efficacy and safety of polyethylene glyco 3350 in the treatment of constipation in children. Pediatr Nurs. 2004;30(3):232-7.

5. Lai EJ, Calderwood AH, Doros G, Fix OK, Jacobson BC. The Boston bowe preparation scale: a valid and reliable instrument for colonoscopy-oriented research. Gastrointest Endosc. 2009;69 (3 Pt 2):620-5.
6. Pashankar DS, Uc A, Bishop WP. Polyethylene glycol 3350 without electrolytes: a new safe, effective, and palatable bowel preparation for colonoscopy in children. J Pediatr. 2004;144(3):358-62.

7. Phatak UP, Johnson S, Husain SZ, Pashankar DS. Two-day bowel preparation with polyethylene glycol 3350 and bisacodyl: a new, safe, and effective regimen for colonoscopy in children. J Pediatr Gastroenterol Nutr. 2011;53(1):71-4.

8. Sorser SA, Konanki V, Hursh A, Hagglund K, Lyons H. 1-day bowel preparation with polyethylene glycol 3350 is as effective and safe as a 3-day preparation for colonoscopy in children. BMC Res Notes. 2014;7:648.

9. Terry NA, Chen-Lim ML, Ely E, Jatla M, Ciavardone D, Esch S, et al. Polyethylene glycol powder solution versus senna for bowel preparation for colonoscopy in children. J Pediatr Gastroenterol Nutr. 2013;56(2)215-9.

10. Walia R, Steffen R, Feinberg L, Worley S, Mahajan L. Tolerability, safety, and efficacy of PEG 3350 as a 1-day bowel preparation in children. J Pediatr Gastroenterol Nutr. 2013;56(2):225-8. 